\title{
Effect of Niobium and Yttrium modified Ti-based bulk amorphous alloy on correlation of plastic deformation energy and ductility \\ Shengfeng Shan ${ }^{1 *}$, Bing Zhang ${ }^{2}$, Yuanzhi Jia ${ }^{2}$ and Mingzhen $\mathbf{M a}^{2}$ \\ 1 Department of Physics, Jining University, Qufu, 273155, China; sdjnssf@163.com \\ 2 State Key Laboratory of Metastable Materials Science and Technology, Yanshan University, Qinhuangdao 066004, China; e-mail@e-mail.com \\ * Correspondence: sdjnssf@163.com; Tel.: 086-0537-8074723
}

\begin{abstract}
A series of $\left.\mathrm{Ti}_{40} \mathrm{Zr}_{25} \mathrm{Cu}_{9} \mathrm{Ni}_{8} \mathrm{Be}_{18}\right)_{100-\mathrm{x}} \mathrm{TM}_{\mathrm{x}}(\mathrm{x}=0,1,2,3,4$ at. $\%, \mathrm{TM}=\mathrm{Nb}, \mathrm{Y})$ Bulk amorphous alloys were designed and prepared using the copper mold casting method. The microstructures, glass forming ability and mechanical properties of the alloys were investigated by means of X-ray diffractometry (XRD), scanning electron microscopy (SEM), transmission electron microscopy (TEM), differential scanning colorimetry (DSC), depth-sensitive nanoindentation and uniaxial compressive test. The Bulk amorphous alloys with different ductility were investigated by measuring their plastic deformation energy (PDE) of the first pop-in events during loading. The relationships between the PDE value, shear band formation and ductility in Bulk amorphous alloys have been investigated. The results show that the PDE value decreases by the $\mathrm{Nb}$ addition and promotes the generation of multiple shear bands easily, which increase the fracture strength and plasticity significantly. Substituting $\mathrm{Nb}$ with $\mathrm{Y}$ has exactly the reverse effect. A useful rule for preparing of Bulk amorphous alloys with high plasticity is herein proposed, whereby the chemical composition of the Bulk amorphous alloys can be tailored to possess a lower PDE value.
\end{abstract}

Keywords: Plastic deformation energy; Nanoindentation; Bulk amorphous alloy; Shear band

\section{Introduction}

Bulk amorphous alloys have excellent properties such as high strength, high hardness and low modulus of elasticity, making them a very good application prospect as structural materials[1-4].Researchers have developed multi-component bulk amorphous alloys such as Pd-based, Zr-based, Fe-based, Co-based, Ni-based and Ti-based[5-7]. However, the plastic rheology of amorphous alloys imited to the shear bands is achieved by localized shear deformation[8,9]. The deformation characteristics of amorphous result in very low room temperature plasticity, which limits its application as structural materials[4]. In recent years, many methods have been used to avoid brittle fracture due to local shear failure and further improve the mechanical properties of bulk amorphous alloys. For instance, the methods include changing the crystallization mode of amorphous alloys by adding elements like $\mathrm{Ag}, \mathrm{Pd}, \mathrm{Au}, \mathrm{Pt}$ or $\mathrm{Y}$ in the preparation of amorphous composite materials[10,11], precipitating quasicrystal or nanocrystals in an amorphous matrix by annealing process and generating ductile phase dendrites in situ from the amorphous matrix by adding high melting-point elements like $\mathrm{Ta}, \mathrm{Nb}$, etc in amorphous alloys[12,13]. The second phase interacts with the shear bands to limit the shear slip of the amorphous matrix on its maximum shear stress surface and improves the plastic deformation ability of the bulk amorphous alloy[14]. The unique atomic structure of amorphous alloy is different from the dislocation and grain boundary defect of crystalline alloy. The generation and expansion of shear bands have a great influence on the plasticity of amorphous alloys and play an important role in the deformation and fracture process of amorphous alloys[15]. 
The nanoindentation of the depth-sensing technology has been applied to measure the mechanical properties of materials[16]. The advantages of nanoindentation technology in testing mechanical properties of materials are as follows: First, compared with traditional measurement techniques, nanoindentation has accurate measurement results of displacement and stress in microscale materials, such as microstructure changes by pressure-induced phase and shape transformation that cannot be involved in traditional techniques[17,18]; The deformation area of nanoindentation measurement is very small, which reduces the influence of material defects on the measurement of mechanical properties[19,20]. It can be used to measure the properties of materials, such as theoretical strength of materials. More importantly, the sawtooth flow (pop-in) during nanoindentation testing is related to plastic deformation[21].The researchers performed nanoindentation tests on Pt-based, Zr-based, Fe-based, Cu-based, and Ni-based amorphous alloys, calculated the actual deformation volume and plastic deformation work caused by the indentation depth during the shear bands generation during compression and obtained the plastic deformation energy (PDE) during deformation[22].

In this paper, the nanoindentation test of $\mathrm{Ti}_{40} \mathrm{Zr}_{25} \mathrm{Cu}_{9} \mathrm{Ni}_{8} \mathrm{Be} 18$ amorphous alloy was carried out by using spherical indenter. The relationship between the addition of $\mathrm{Nb} / \mathrm{Y}$ and the PDE, shear bands formation, and plastic deformation of amorphous alloy was also studied.

\section{Materials and Methods}

$\mathrm{Zr}, \mathrm{Ti}, \mathrm{Cu}, \mathrm{Ni}, \mathrm{Be}, \mathrm{Nb}$ and $\mathrm{Y}$ pure metals were melted by electric arc under the protection of high purity argon gas, and at least three times of smelting to ensure the uniformity of chemical composition. Then, a plurality of alloy rods having a diameter of $3 \mathrm{~mm}$ and having a composition of $\left.\mathrm{Ti}_{40} \mathrm{Zr}_{25} \mathrm{Cu}_{9} \mathrm{Ni}_{8} \mathrm{Be}_{18}\right)_{100-\mathrm{x}} \mathrm{TM} \times(\mathrm{x}=0,1,2,3,4$ at. $\%, \mathrm{TM}=\mathrm{Nb}, \mathrm{Y})$ were prepared by copper mold cooling. The D/max-2500/pc X-ray diffractometer of Japan Ricoh was used to conduct diffraction analysis on the cross section of the sample; The microstructure of the sample was observed by JEM-2010 high-resolution transmission electron microscope. The sample was cut into a cylindrical sample of $\varnothing=3 \mathrm{~mm}, \mathrm{~L}=6 \mathrm{~mm}$. The room temperature quasi-static compression test was carried out at a strain rate of $2 \times 10-4$ by MTS810 test machine, and the sample was deformed until fracture occurred. The fracture morphology was observed by KYKY-2800 scanning electron microscope. The MTS nanoindentation system instrument (Nano Indenter XP MTS Ltd., American) was equipped with a spherical indenter with a nominal radius of $10.8 \mu \mathrm{m}$ for nanoindentation testing. The loading rate is $1 \mathrm{mN} / \mathrm{s}$ at room temperature. Before the test, the surface of the sample was carefully polished to flawless. Each sample was tested at least 20 times with a spacing of approximately 20 microns between adjacent indentations.

\section{Results}

\subsection{Amorphous forming ability of alloy}

Figure 1. is the $\mathrm{X}$-ray analysis of $\mathrm{Ti}_{40} \mathrm{Zr}_{25} \mathrm{Cu}_{9} \mathrm{Ni}_{8} \mathrm{Be}{ }_{18}$, (Ti40 $\left.\mathrm{Zr}_{25} \mathrm{Cu}_{9} \mathrm{Ni}_{8} \mathrm{Be}_{18}\right)_{97} \mathrm{Nb}_{3}$, ( $\left.\mathrm{Ti}_{40} \mathrm{Zr}_{25} \mathrm{Cu}{ }_{9} \mathrm{Ni}_{8} \mathrm{Be}_{18}\right)_{99} \mathrm{Y}_{1}$ and $\left(\mathrm{Ti}_{40} \mathrm{Zr}_{25} \mathrm{Cu}_{9} \mathrm{Ni}_{8} \mathrm{Be}_{18}\right)_{98} \mathrm{Y}_{2}$. The diffraction spectra of $\mathrm{Ti}_{40} \mathrm{Zr}_{25} \mathrm{Cu}_{9} \mathrm{Ni}_{8} \mathrm{Be}_{18}$, ( $\left.\mathrm{Ti}_{40} \mathrm{Zr}_{25} \mathrm{Cu}{ }_{9} \mathrm{Ni}_{8} \mathrm{Be}_{18}\right)_{97} \mathrm{Nb}_{3}$, ( $\left.\mathrm{Ti}_{40} \mathrm{Zr}_{25} \mathrm{Cu}_{9} \mathrm{Ni}_{8} \mathrm{Be}_{18}\right)_{99} \mathrm{Y}_{1}$ alloys only contain a wide diffuse scattering peak, and there are no obvious sharp diffraction peaks of crystal phase, which are typical amorphous diffraction patterns. The diffraction patterns and HRTEM images of the three alloy samples were further observed by transmission electron microscopy (TEM). It was found that the microstructure was uniform and single-phase structure without precipitation of crystal phase and the diffraction of selected region was a typical amorphous diffraction ring. However, the diffraction spectrum of the ( $\left.\mathrm{Ti}_{40} \mathrm{Zr}_{25} \mathrm{Cu}{ }_{9} \mathrm{Ni}_{8} \mathrm{Be}_{18}\right)_{98} \mathrm{Y}_{2}$ alloy shows that the crystallization peak is superimposed on the broad diffuse scattering peak, indicating that the crystallization occurs when the $Y$ element content is $2 \%$, which is not completely amorphous. As the content of $Y$ element increases, the crystallization peak of the XRD pattern of the alloy sample becomes more and more obvious (the results are not shown in the figure). The results show that the addition of $\mathrm{Y}$ element obviously induces the precipitation of crystallization phase and reduces the amorphous forming ability of the alloy. Further DSC analysis 
95

96

97

showed that the melting point, glass transition temperature and crystallization temperature of the alloy were equal regardless of the amount of $\mathrm{Nb}$ added (results not shown), indicating that the addition of $\mathrm{Nb}$ element did not significantly affect the amorphous forming ability of the alloy.

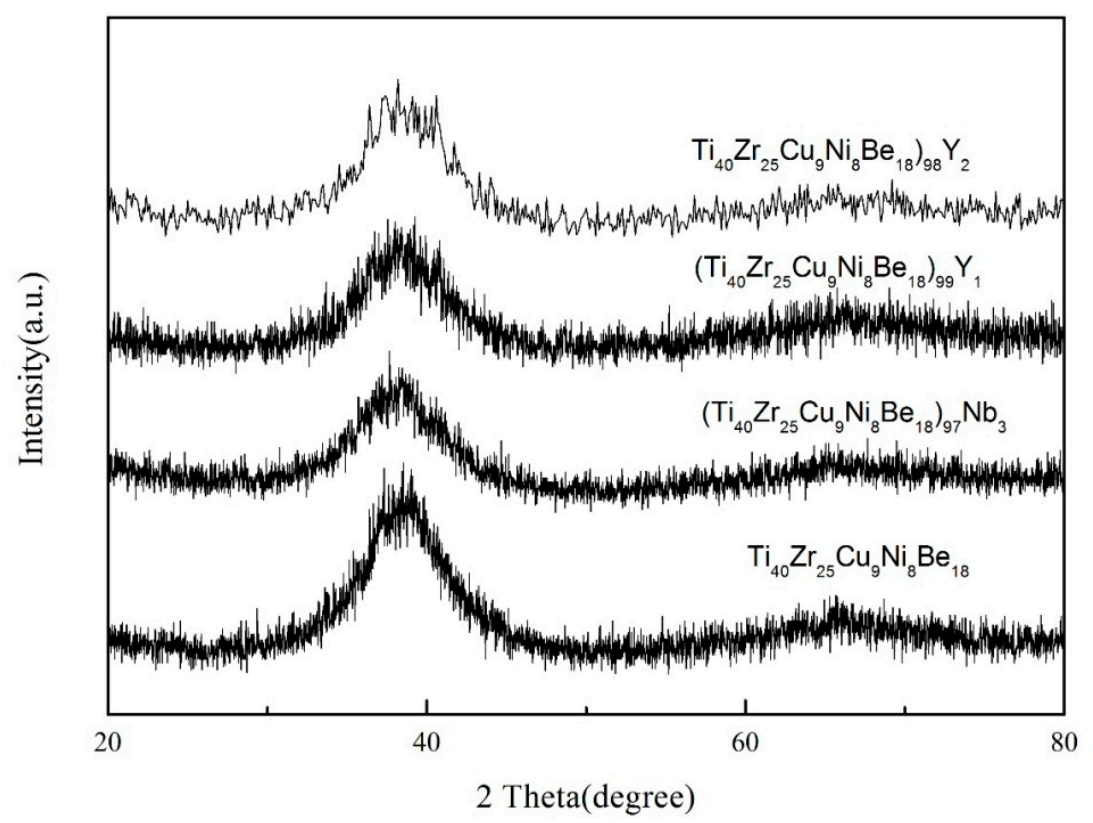

Figure. 1 XRD patterns of the as-cast $\left(\mathrm{Ti}_{40} \mathrm{Zr}_{25} \mathrm{Cu}{ }_{9} \mathrm{Ni}_{8} \mathrm{Be} 18\right){ }_{100-\mathrm{x}} \mathrm{TM}(\mathrm{x}=0,1,2,3,4$ at. $\%, \mathrm{TM}=\mathrm{Nb}, \mathrm{Y})$ Alloys.

\subsection{Macro compression performance of amorphous alloys}

Figure 2. is a compressive stress-strain curve of an as-cast alloy at room temperature after addition of $\mathrm{Nb}$ or $\mathrm{Y}$ element to $\mathrm{Ti}_{40} \mathrm{Zr}_{25} \mathrm{Cu}_{9} \mathrm{Ni}_{8} \mathrm{Be}_{18}$. The room temperature compression mechanical properties of several alloys are summarized in Table 1. The stress-strain curve shows that the compressive fracture strength of Ti40Zr25Cu9Ni8Be18 amorphous alloy is $1896 \mathrm{MPa}$ and the plastic deformation is $2.1 \%$. After adding $\mathrm{Nb}$ element, the fracture ultimate strength of $\left(\mathrm{Ti}_{40} \mathrm{Zr}_{25} \mathrm{Cu}_{9} \mathrm{Ni}_{8} \mathrm{Be}_{18}\right)_{97} \mathrm{Nb}_{3}$ as-cast amorphous alloy reach $2177 \mathrm{MPa}$, and the plastic deformation is up to $13 \%$. However, $\left(\mathrm{Ti}_{40} \mathrm{Zr}_{25} \mathrm{Cu}_{9} \mathrm{Ni}_{8} \mathrm{Be}_{18}\right){ }_{99} \mathrm{Y}_{1}$ amorphous alloy has a breaking strength of $1990 \mathrm{MPa}$ and plastic strain of only $1.1 \%$. For ( $\left.\mathrm{Ti}_{40} \mathrm{Zr}_{25} \mathrm{Cu}_{9} \mathrm{Ni}_{8} \mathrm{Be}_{18}\right)_{98} \mathrm{Y}_{2}$ crystal alloy, the compression rupture strength is $1819 \mathrm{MPa}$ and plastic deformation is only $0.1 \%$, almost no plasticity; ( $\mathrm{Ti}_{40} \mathrm{Zr}_{25} \mathrm{Cu}_{9} \mathrm{Ni}_{8} \mathrm{Be}_{18}$ ) ${ }_{96} \mathrm{Nb}_{4}$ amorphous alloy has a breaking strength of $1930 \mathrm{MPa}$ and a plastic strain of $8 \%$. The results show that the plastic strain of the alloy has a strong dependence on trace elements. It is well known that the main mechanism of plasticity improvement of amorphous alloys is that tiny primary phase precipitated during cooling and tiny second phase added are uniformly distributed in the amorphous matrix. The $\mathrm{Ti}_{40} \mathrm{Zr}_{25} \mathrm{Cu}_{9} \mathrm{Ni}_{8} \mathrm{Be}_{18}$ alloy and its $\mathrm{Nb}$ element added alloy didn't find crystallization region or crystalline phase, and thus the increase in plasticity should not be attributed to the result of forming the second phase composite. Unlike crystalline alloys, amorphous alloys have no defects such as dislocations and grain boundaries. The inherent instability of plastic deformation of amorphous alloys is related to the shear bands formed by highly localized shear deformation during plastic deformation. Shear bands are closely related to the zigzag rheology (or first pop-in) in the plastic deformation of the nanoindentation test. In order to clarify the relationship between plastic strain and element addition during compression of amorphous alloy, three amorphous alloys $\mathrm{Ti}_{40} \mathrm{Zr}_{25} \mathrm{Cu}_{9} \mathrm{Ni}_{8} \mathrm{Be}_{18}$, ( $\left.\mathrm{Ti}_{40} \mathrm{Zr}_{25} \mathrm{Cu}_{9} \mathrm{Ni}_{8} \mathrm{Be}_{18}\right)_{97} \mathrm{Nb}_{3}$ and $\left(\mathrm{Ti}_{40} \mathrm{Zr}_{25} \mathrm{Cu}_{9} \mathrm{Ni}_{8} \mathrm{Be}_{18}\right)_{99} \mathrm{Y}_{1}$ were studied to the first pop-in event by nanoindentation test. Combined with the macroscopic compression characteristics, the plastic deformation mechanism of the amorphous alloy is analyzed and calculated by the nanoindentation test. 
Table 1. Compressive mechanical property parameters of the four samples

\begin{tabular}{ccccc}
\hline Alloy & $\boldsymbol{\sigma y}(\mathbf{M P a})$ & $\boldsymbol{\sigma}(\mathbf{M P a})$ & $\boldsymbol{\varepsilon p}(\%)$ & $\varepsilon(\%)$ \\
\hline $\mathrm{Ti}_{40} \mathrm{Zr}_{25} \mathrm{Cu}{ }_{9} \mathrm{Ni}_{8} \mathrm{Be}_{18}$ & 1773 & 1896 & 2.1 & 5.1 \\
$\left(\mathrm{Ti}_{40} \mathrm{Zr}_{25} \mathrm{Cu}{ }_{9} \mathrm{Ni}_{8} \mathrm{Be}_{18}\right)_{97} \mathrm{Nb}_{3}$ & 1769 & 2177 & 13 & 16 \\
$\left(\mathrm{Ti}_{40} \mathrm{Zr}_{25} \mathrm{Cu}{ }_{9} \mathrm{Ni}_{8} \mathrm{Be}_{18}\right)_{97} \mathrm{Nb}_{4}$ & 1675 & 1934 & 8 & 11 \\
$\left(\mathrm{Ti}_{40} \mathrm{Zr}_{25} \mathrm{Cu}{ }_{9} \mathrm{Ni}_{8} \mathrm{Be}_{18}\right)_{99} \mathrm{Y}_{1}$ & 1740 & 1870 & 1.1 & 4.0 \\
$\left(\mathrm{Ti}_{40} \mathrm{Zr}_{25} \mathrm{Cu}{ }_{9} \mathrm{Ni}_{8} \mathrm{Be}_{18}\right)_{98} \mathrm{Y}_{2}$ & 1801 & 1819 & 0.1 & 3 \\
\hline
\end{tabular}

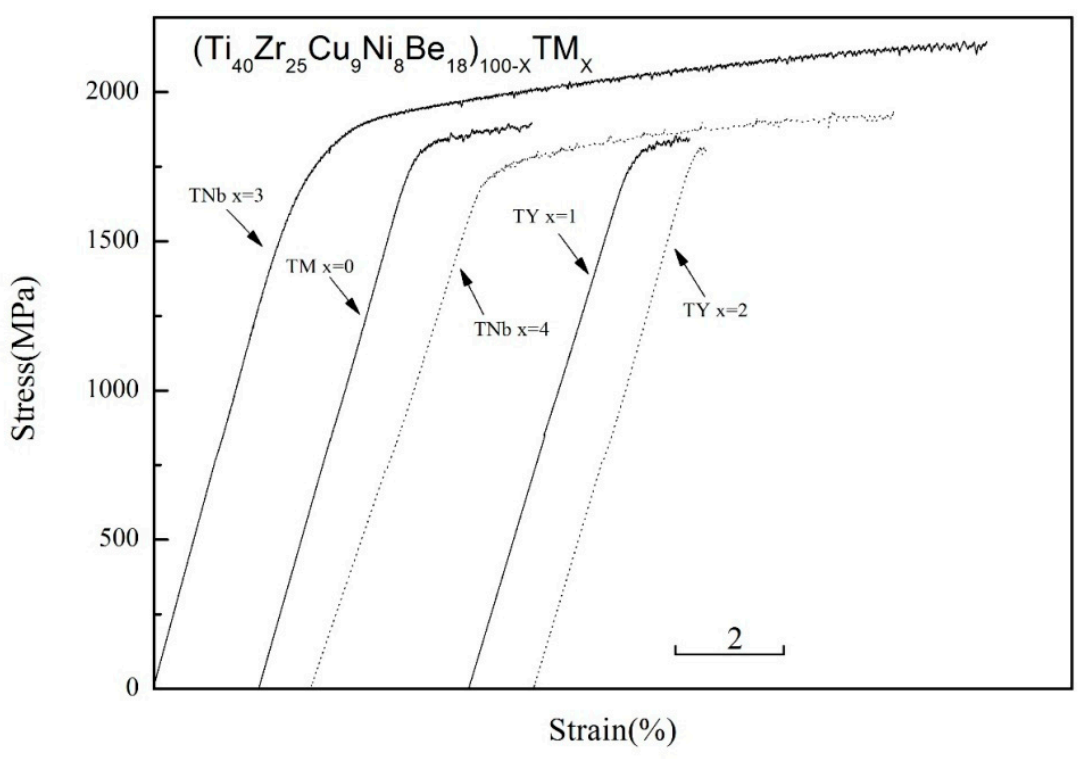

Figure 2. Compressive stress-strain curves of the as-cast $\left(\mathrm{Ti}_{40} \mathrm{Zr}_{25} \mathrm{Cu}{ }_{9} \mathrm{Ni}_{8} \mathrm{Be} 18\right){ }_{100-x} \mathrm{TM} \times(\mathrm{x}=0,1,2,3,4$ at. $\%, \mathrm{TM}=\mathrm{Nb}, \mathrm{Y})$ Alloys.

\subsection{Plastic deformation energy of amorphous alloy}

The basic method of nanoindentation testing technology is to continuously measure the relationship between the force and the indentation depth during the nanoindentation testing and to calculate mechanical performance indicators by the load-displacement curve.

According to the contact theory of the elastic material[23], the elastic modulus E of the material follow formula:

$$
\frac{1}{E_{r}}=\frac{1-\mathcal{v}_{i}^{2}}{E_{i}}+\frac{1-v_{s}^{2}}{E_{s}}
$$

Er is the theoretical elastic modulus of the material, Es is the measured elastic modulus of the material, and the elastic modulus of the diamond indenter is $\mathrm{Ei}=1141 \mathrm{GPa}, \mathrm{Vi}=0.07[24]$ and $\mathrm{Vs}$ are the diamond indenter and the Poisson's ratio of the sample to be tested.The theoretical modulus Er[24] of the material follows formula: 


$$
E_{r}=\frac{\sqrt{\pi}}{2 \beta} \times \frac{s}{\sqrt{A}}
$$

$\mathrm{S}$ is the contact stiffness, $\mathrm{s}=\mathrm{dp} / \mathrm{dh}$ is the slope of the nanoindentation unloading curve, and $\beta$ is the folding coefficient, which is related to the geometry of the indenter. For cone indenters, $\beta=1.034$, cylindrical indenter $\beta=1$. Figure 3. shows a typical nanoindentation load-displacement (p-h) curve of ( $\left.\mathrm{Ti}_{40} \mathrm{Zr}_{25} \mathrm{Cu}_{9} \mathrm{Ni}_{8} \mathrm{Be}_{18}\right)_{97} \mathrm{Nb}_{3}$, including loading and unloading (indicated by the arrows in the figure). The starting point of plastic deformation occurring during loading can be determined by the experimental data from the first point of the elastic theoretical curve (shown by the dashed curve in Figure 3.) given by Hertz theory.

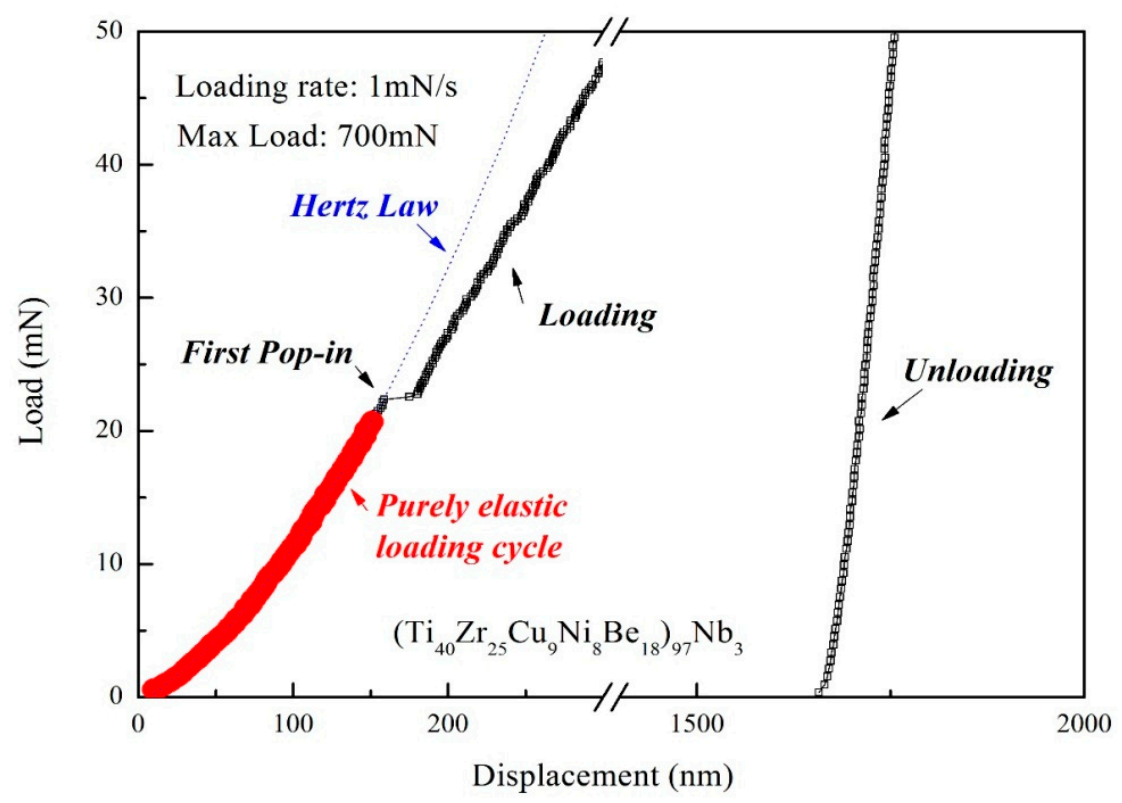

Figure 3. A load-displacement (P-h) curve of ( $\left.\mathrm{Ti}_{40} \mathrm{Zr}_{25} \mathrm{Cu}_{9} \mathrm{Ni}_{8} \mathrm{Be}_{18}\right)_{97} \mathrm{Nb}_{3}$ bulk amorphous alloy at the loading rate of $1 \mathrm{mN} / \mathrm{s}$. To better illustrate the initial deviation from elastic contact, the plot here is magnified, as predicted using the Hertzian contact law shown as the dash line. The first 'pop-in' event corresponds to a discontinuity, denoted by the arrow.

Nanoindentation tests performed on lower subcritical loads typically exhibit desirable reversibility and leave no trace on the surface of the sample. When the load reach approximately 22 $\mathrm{mN}$, the clusters under the indenter suddenly collapse to relieve Strain, which causes the first pop-in of displacement (indicated by the arrow) and marks the beginning of an irreversible shaping rheology. In addition, the first pop-in of displacement also indicates the generation of shear bands.The load-displacement curve of the spherical indenter nanoindentation before the first "pop-in" appeared in accordance with the Kurz [19] elastic contact law:

$$
F=\frac{4}{3} E_{r} \sqrt{R h^{2}}
$$

$\mathrm{R}$ is the nominal radius of the indenter. $\mathrm{Ht}$ is the indentation displacement of first pop-in, hc is the indenter contact displacement, and the relationship is shown in Figure 4: 


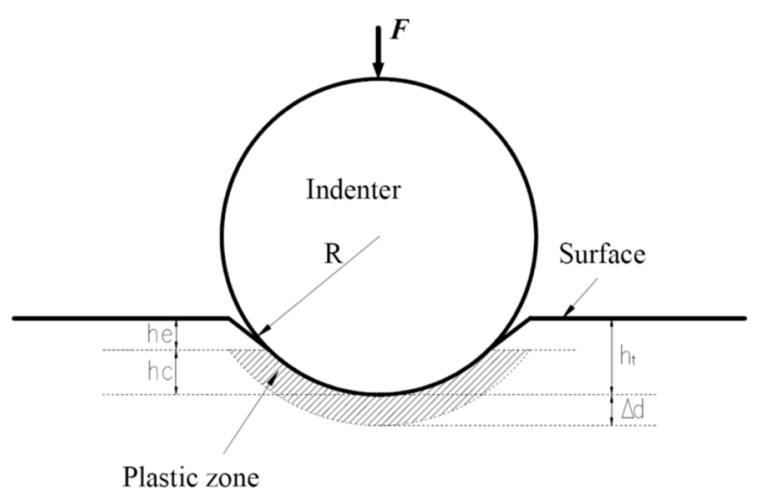

Figure 4. spherical indentation geometry, where ht is the indenter displacement at the beginning of first pop-in, hc is contact depth, he is surface displacement, and $\Delta d$ is the suddenly displacement of indenter during the first pop-in[22].

$$
h_{c}=h_{t}-\varepsilon \frac{F_{\max }}{s} \sqrt{\frac{F_{p}}{F_{\text {max }}}}
$$

$F_{\max }$ is the maximum load, $\varepsilon$ is the reduction factor of the geometry indenter, $\mathrm{Fp}$ is the load of the first pop-in, and $\Delta \mathrm{d}$ is the displacement of the first pop-in. The average contact stress Pm of the first pop-in is[19]:

$$
P_{m}=\left(\frac{16 F_{p} E_{r}{ }^{2}}{9 \pi^{3} R^{2}}\right)^{\frac{1}{3}}
$$

Figure 5 shows the load portion of a typical nanoindentation P-h curve of Ti40Zr25Cu9Ni8Be18, ( $\left.\mathrm{Ti}_{40} \mathrm{Zr}_{25} \mathrm{Cu}{ }_{9} \mathrm{Ni}_{8} \mathrm{Be}_{18}\right)_{97} \mathrm{Nb}_{3}$ and $\left(\mathrm{Ti}_{40} \mathrm{Zr}_{25} \mathrm{Cu}_{9} \mathrm{Ni}_{8} \mathrm{Be}_{18}\right)_{99} \mathrm{Y}_{1}$. It can be seen from Figure 5 that the load (Fp), the indenter displacement $(\mathrm{ht})$ and the displacement of first pop-in $(\Delta \mathrm{d})$ are significantly different to the first pop-in in the three alloys. The sawtooth phenomenon can be clearly observed in the three $\mathrm{P}-\mathrm{h}$ curves, indicating that the deformation process is interrupted by many pop-in during the loading process. Figure 4 . shows enlarged images corresponding to the P-h curve at the first pop-in of $a, b$ and c, respectively. When the sawtooth area was further enlarged, it was found that the few of dots recorded in the sawtooth area, which means that the sawtooth flow rate was faster. In compression deformation, each serration corresponds to the nucleation of the shear bands and quickly adapts to plastic strain, causing drop in load [25]. $\mathrm{Ti}_{40} \mathrm{Zr}_{25} \mathrm{Cu}{ }_{9} \mathrm{Ni}_{8} \mathrm{Be}_{18}$ bulk amorphous alloy with no added element, which corresponds to the load (Fp), indenter displacement (ht) and displacement $(\Delta \mathrm{d})$ at the first pop-in, is $44 \mathrm{mN}, 270 \mathrm{~nm}$ and $9.5 \mathrm{~nm}$, respectively. The bulk amorphous alloy of adding $\mathrm{Nb}$ element reduced $\mathrm{Fp}$ to $22 \mathrm{mN}$ and $\Delta \mathrm{d}$ increased to $22 \mathrm{~nm}$, indicating that the displacement of first pop-in is easy to start. On the contrary, the BMG of adding the Y element increased $\mathrm{Fp}$ to $49 \mathrm{mN}$ and the $\Delta \mathrm{d}$ is almost unchanged, indicating that the addition of $\mathrm{Y}$ element for bulk amorphous alloy requires a greater stress drive to cause the first pop-in. Table 2 is the measured values of load and displacement for the first displacement of the sample (average over 10 experimental measurements).

$$
W_{p}=F_{p} \Delta d
$$

The volume of the plastic deformation zone is shown in the shaded part of Figure 4 by[22]: 
$$
V_{p}=V_{\left(h_{c}+\Delta d\right)}-V_{h_{c}}=\frac{\pi\left(h_{c}+\Delta d\right)}{6}\left[3 R^{2}+\left(h_{c}+\Delta d\right)\right]-\frac{\pi h_{c}}{6}\left(3 R^{2}+h_{c}^{2}\right)
$$

199

Table 2. The measured indenter displacement $\left(h_{\mathrm{t}}\right)$, contact depth of $h_{\mathrm{t}}\left(h_{\mathrm{c}}\right)$, suddenly displacement of indenter $(\Delta d)$, applied forces $\left(F_{\mathrm{p}}\right)$, contact pressure $\left(P_{\mathrm{m}}\right)$ and critical shear stresses $\left(\tau_{\text {crit }}\right)$ at the first pop-in events of the three samples.

\begin{tabular}{ccccccc}
\hline Alloy & $\boldsymbol{h}_{\mathrm{t}}$ & $\boldsymbol{h}_{\mathrm{c}}$ & $\boldsymbol{F}_{\mathrm{p}}(\mathbf{m N})$ & $\boldsymbol{\Delta} \boldsymbol{d}(\mathbf{n m})$ & $\boldsymbol{P}_{\mathrm{m}}(\mathrm{GPa})$ & $\boldsymbol{\tau}_{\text {crit }}(\mathrm{GPa})$ \\
\hline $\mathrm{Ti}_{40} \mathrm{Zr}_{25} \mathrm{Cu}_{9} \mathrm{Ni}_{8} \mathrm{Be}_{18}$ & 270.41 & 153.93 & 43.73 & 7.56 & 6.54 & 2.91 \\
$\left(\mathrm{Ti}_{40} \mathrm{Zr}_{25} \mathrm{Cu}_{9} \mathrm{Ni}_{8} \mathrm{Be}_{18}\right)_{97} \mathrm{Nb}$ & 146.43 & 69.88 & 19.34 & 17.12 & 4.98 & 2.22 \\
$\left(\mathrm{Ti}_{40} \mathrm{Zr}_{25} \mathrm{Cu}_{9} \mathrm{Ni}_{8} \mathrm{Be}_{18}\right)_{99} \mathrm{Y}_{1}$ & 340.72 & 210.52 & 55.48 & 6.36 & 7.08 & 3.10 \\
\hline
\end{tabular}

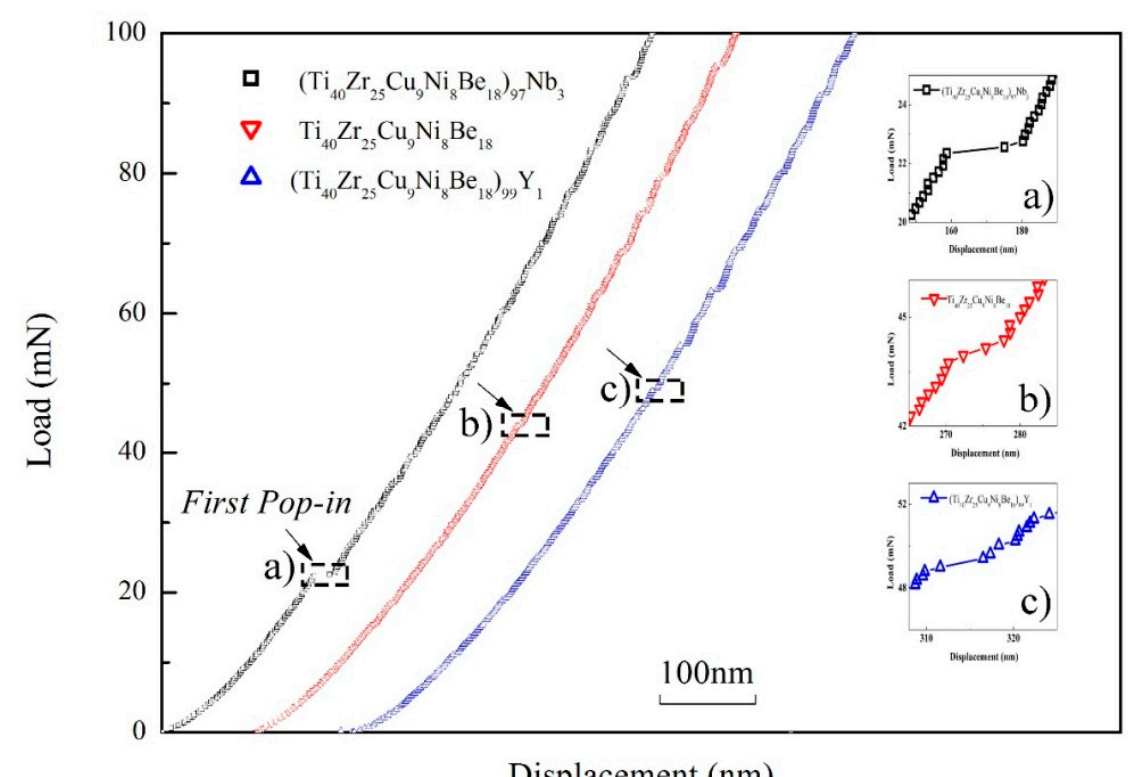

Figure 5. Typical loading parts of the nanoindentation load-displacement curves of $\left(\mathrm{Ti}_{40} \mathrm{Zr}_{25} \mathrm{Cu}_{9} \mathrm{Ni}_{8} \mathrm{Be}_{18}\right)_{100-\mathrm{x}} \mathrm{TM}_{\mathrm{x}}(\mathrm{x}=0,1,3$ at. $\%, \mathrm{TM}=\mathrm{Nb}, \mathrm{Y})$ glassy rod samples at the loading rate of 1 $\mathrm{mN} / \mathrm{s}$.As the indentation depth increases, the deformation volume increases, and the total plastic deformation work of the first "pop-in" occurs[22]:

Therefore, the first "pop-in" PDE can be calculated by[22]:

$$
U=\frac{W_{p}}{V_{p}}
$$

The PDE measured results of three amorphous alloy samples are shown in Table 3.

Table 3. The calculated plastic deformation energy of the three samples

\begin{tabular}{ccccc}
\hline Alloy & $W \mathbf{p}(\mathrm{J})$ & $V \mathbf{p}(\mathbf{m} 3)$ & $W \mathbf{p} / \mathbf{p}(\mathrm{J} / \mathbf{m} 3)$ & $\varepsilon(\%)$ \\
\hline Pt-based[22] & $1.985 \mathrm{E}-11$ & $1.57 \mathrm{E}-19$ & $1.26 \mathrm{E} 8$ & 20 \\
Cu50Zr50[22] & $3.28 \mathrm{E}-11$ & $1.92 \mathrm{E}-19$ & $1.71 \mathrm{E} 8$ & 30 \\
Zr-based[22] & $7.25 \mathrm{E}-10$ & $1.61 \mathrm{E}-18$ & $4.52 \mathrm{E} 8$ & 0.2 \\
\hline
\end{tabular}




\begin{tabular}{ccccc}
\hline Cu-based[22] & $3.76 \mathrm{E}-10$ & $9.05 \mathrm{E}-19$ & $4.15 \mathrm{E} 8$ & 1.6 \\
$\mathrm{Ti}_{40} \mathrm{Zr}_{25} \mathrm{Cu}_{9} \mathrm{Ni}_{8} \mathrm{Be}_{18}$ & $3.31 \mathrm{E}-10$ & $1.38 \mathrm{E}-18$ & $2.39 \mathrm{E} 8$ & 2.1 \\
$\left(\mathrm{Ti}_{40} \mathrm{Zr}_{25} \mathrm{Cu}_{9} \mathrm{Ni}_{8} \mathrm{Be}_{18}\right)_{97} \mathrm{Nb}_{3}$ & $3.29 \mathrm{E}-10$ & $3.13 \mathrm{E}-18$ & $1.05 \mathrm{E} 8$ & 13 \\
$\left(\mathrm{Ti}_{40} \mathrm{Zr}_{25} \mathrm{Cu}{ }_{9} \mathrm{Ni}_{8} \mathrm{Be}{ }_{18}\right)_{99} \mathrm{Y}_{1}$ & $3.53 \mathrm{E}-10$ & $1.17 \mathrm{E}-18$ & $3.03 \mathrm{E} 8$ & 1.1 \\
\hline
\end{tabular}
the first pop-in; U: the PDE calculated from nanoindentation, $=W p / V p ; \varepsilon$ : plastic strain

\section{Discussion}

The atoms of portion move larger displacement than the surrounding atoms by shear deformation. These atoms of portion with the surrounding atoms are called the shear transition zone (STZ). D. Pan[18] showed that the size of the STZ is fundamentally related to the plasticity of amorphous alloys. When the amorphous alloy has low plastic deformation energy, its STZ is large in size, and it is easy to produce shear bands (low energy threshold), showing a certain plastic deformation ability. Plastic amorphous alloys have low plastic deformation energy because of their large STZ. Therefore, it is easy to produce a shear band (low energy threshold). It is well known that the cross-sectional morphology is related to the mechanical properties of the material. The section morphology rich in shear bands is related to ductile fracture, while the section morphology of cleavage fracture is brittle fracture, depending on the size of plastic deformation energy (PDE). In order to clarify the deformation mechanism of the three-component amorphous alloy, the morphology of the fracture surface and side of the ( $\left.\mathrm{Ti}_{40} \mathrm{Zr}_{25} \mathrm{Cu}{ }_{9} \mathrm{Ni} \mathrm{Be}_{18}\right){ }_{97} \mathrm{Nb}_{3}$ sample is shown in Figure 6a. A large number of shear bands in many directions are distributed on the side of the sample as shown in Figure 6a. In the initial stage of deformation, the main shear bands are difficult to spread on the amorphous matrix. Therefore, it is limited to a certain region, and the plastic strain of the amorphous matrix cannot be continuously performed.
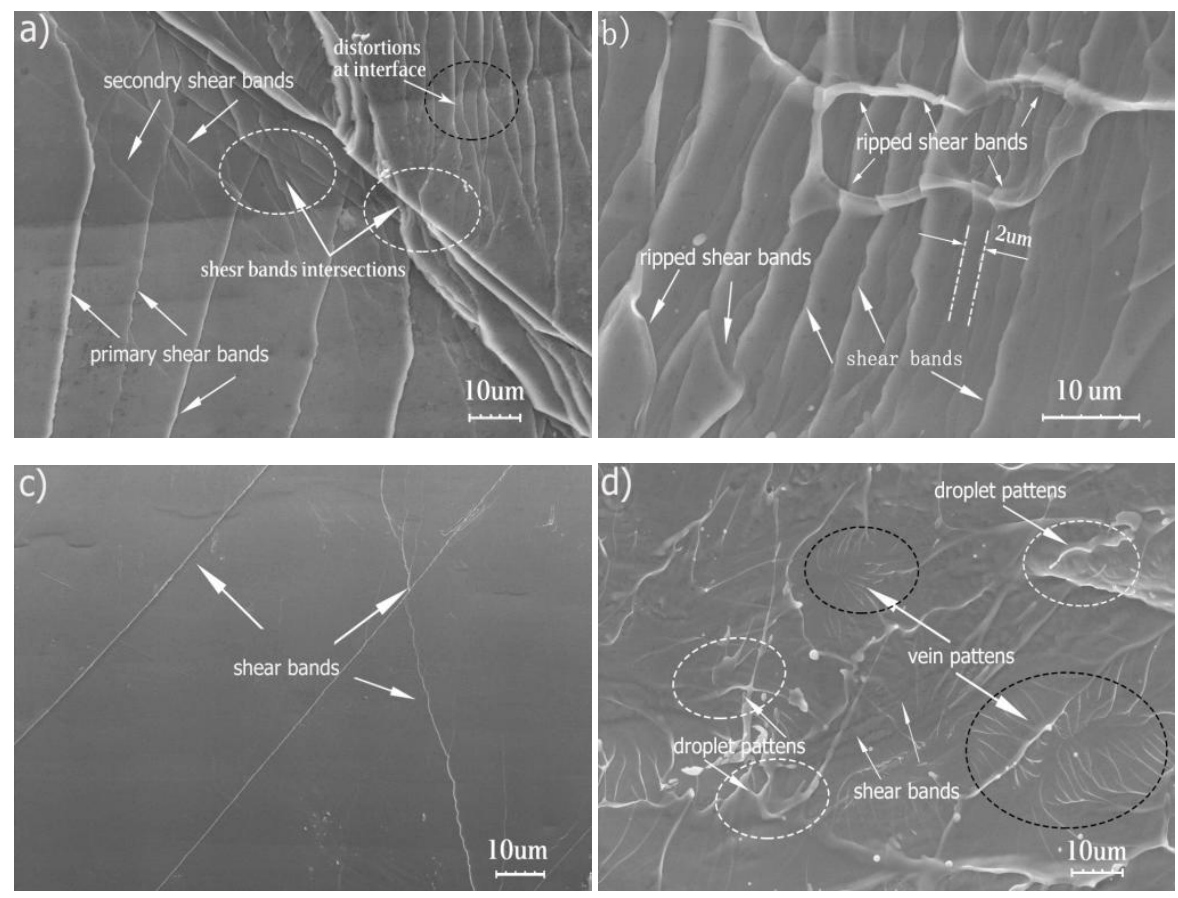

Figure 6. SEM images of the fractography for the compressive fracture samples of the ( $\left.\mathrm{Ti}_{40} \mathrm{Zr}_{25} \mathrm{Cu} \mathrm{CuNi}_{8} \mathrm{Be}{ }_{18}\right)_{97} \mathrm{Nb}_{3}$ bulk amorphous alloy: (a) lateral surface, (b) fracture surface; ( $\left.\mathrm{Ti}_{40} \mathrm{Zr}_{25} \mathrm{Cu}{ }_{9} \mathrm{Ni}_{8} \mathrm{Be} 18\right)_{99} \mathrm{Y}_{1}$ : (c) lateral surface, (d) fracture surface. 
deformation energy. When the secondary shear bands expand through the main shear bands, it will be blocked and interact. From Figure 6b, the intensive interaction between the shear bands can be seen. The spacing of the secondary shear band is only 1-2um, indicating that the amorphous sample has intense plastic deformation. That is, the main shear bands effectively block the secondary shear bands. The shear strain in the deformation process is accommodated by the generation and stable extension of a plurality of shear bands, which ultimately leads to higher macroscopic compression ductility.

The plasticity of amorphous alloy is reduced by $\mathrm{Y}$ instead of $\mathrm{Nb}$. The SEM image of the cross section and side of the $\left(\mathrm{Ti}_{40} \mathrm{Zr}_{25} \mathrm{Cu}_{9} \mathrm{Ni}_{8} \mathrm{Be}_{18}\right)_{99} \mathrm{Y}_{1}$ is shown in Figure $6 \mathrm{c}$ and Figure $6 \mathrm{~d}$. A little of shear bands are distributed on the side of the sample from Figure $6 \mathrm{c}$ of arrow. From the surface of the fracture, three fracture morphologies can be observed: the droplet pattern (white ellipse), the vein pattern (black ellipse) and the shear step (white arrow). The existence of more droplet patterns is due to the elastic energy existing in the deformation process. When the sample breaks, the heat released in a relatively narrow space and short time cause to re-melt part of the amorphous matrix[26]. A few vein patterns are formed during the gradual sliding expansion of the main shear bands due to the obstruction (and absorption) of the shear bands by the amorphous matrix. In addition, the appearance of the shearing step on the fracture surface indicates that the amorphous matrix fail to effectively hinder the expansion of the shear bands and the subsequent cracking. On the other hand, due to the increase in the instantaneous temperature of the crack (adiabatic exotherm), micro-scale vein pattern is produced. Since only a little of shear bands is generated, the plastic rheology is confined within the main shear bands. As the addition of the $\mathrm{Y}$ element, $\left(\mathrm{Ti}_{40} \mathrm{Zr}_{25} \mathrm{Cu}_{9} \mathrm{Ni}_{8} \mathrm{Be}_{18}\right)_{99} \mathrm{Y}_{1}$ amorphous alloy shows a lower plasticity than $\left(\mathrm{Ti}_{40} \mathrm{Zr}_{25} \mathrm{Cu}_{9} \mathrm{Ni}_{8} \mathrm{Be}_{18}\right)_{97} \mathrm{Nb}_{3}$.

The plasticity in the crystalline material is related to dislocation defects, while the plastic deformation of the amorphous alloy is confined to the narrow shear bands with gathering too many disordered atoms. It is well known that bulk amorphous alloys are compressed to high stress at room temperature, and the plastic strain is confined within the nano-sized shear bands region, causing catastrophic fracture in a non-uniform strain manner. On the other hand, the atoms are rearranged in a short range during the deformation process, and excess free volume is accumulated[27], resulting in the formation of FVAZs (free volume accumulation zones). In the process of deformation, the shear transition zone is easily generated in FVAZs with a very small energy barrier and the nucleation zone of the shear bands. It is easy to reach the required shear stress value during the deformation process of the relatively loosely dispersed atomic group, so that the adjacent atoms are rearranged to reach the shear strain to form STZs. The generation and development of STZs is strongly influenced by the local atomic arrangement, in which the relatively loose position of deposited atomic is susceptible to shear strain under the shear stress. The shear bands propagation is to be triggered by meeting of shear bands with each other, which increases the fluidity of the bulk amorphous alloy plastic deformation and produces an overall ductility with large plastic strain. Furthermore, it is well known that displacement of pop-in during nanoindentation actually corresponds to the formation of shear bands by nanoindentation test[28]. Pack and Schuh's result[29]revealed the formation of shear bands (or first pop-in) controlled by higher stress along a feasible shear plane in nanoindentation test of spherical indenter. Shear bands are formed when the stress reaches a critical threshold, rather than being controlled by the highest stress near the principal stress. The ability of plastic deformation of metallic glass depends on the nucleation and proliferation of shear bands during deformation. In the nanoindentation experiment, Pop-in in the load-displacement curve indicates material strain and the generation and expansion of the shear bands. In this study, the PDE values of $\mathrm{Ti}_{40} \mathrm{Zr}_{25} \mathrm{Cu}_{9} \mathrm{Ni}_{8} \mathrm{Be}_{18}$, (Ti40 $\left.\mathrm{Zr}_{25} \mathrm{Cu}_{9} \mathrm{Ni}_{8} \mathrm{Be}_{18}\right)_{97} \mathrm{Nb}_{3}$ and $\left(\mathrm{Ti}_{40} \mathrm{Zr}_{25} \mathrm{Cu}_{9} \mathrm{Ni}_{8} \mathrm{Be}_{18}\right)_{99} \mathrm{Y}_{1}$ were $2.39 \mathrm{E} 8 \mathrm{~J} / \mathrm{m} 3,1.05 \mathrm{E} 8 \mathrm{~J} / \mathrm{m} 3,3.03 \mathrm{E} 8 \mathrm{~J} / \mathrm{m} 3$, respectively. If the PDE value of the $\mathrm{Ti}_{40} \mathrm{Zr}_{25} \mathrm{Cu}_{9} \mathrm{Ni}_{8} \mathrm{Be}_{18}$ sample is assumed to be a1, the PDE values of the ( $\left.\mathrm{Ti}_{40} \mathrm{Zr}_{25} \mathrm{Cu}_{9} \mathrm{Ni}_{8} \mathrm{Be}_{18}\right)_{97} \mathrm{Nb}_{3}$ and $\left(\mathrm{Ti}_{40} \mathrm{Zr}_{25} \mathrm{Cu}_{9} \mathrm{Ni}_{8} \mathrm{Be}_{18}\right)_{99} \mathrm{Y}_{1}$ samples can be estimated to be $0.43 \mathrm{a} 1$ and $1.3 \mathrm{a} 1$, respectively. It is clear that the PDE value is reduced by $57 \%$ after the addition of $\mathrm{Nb}$. Conversely, the PDE value increases by $30 \%$ after the addition of Y. Wang pointed out that the PDE value of bulk amorphous alloy s is intrinsically related to the formation ability of shear bands and directly related to the plastic 
deformation ability of bulk amorphous alloys. In summary, the shear bands will nucleate in these STZs when the stress or deformation energy exceeds a threshold during plastic deformation. ( $\mathrm{Ti}_{40} \mathrm{Zr}_{25} \mathrm{Cu}_{9} \mathrm{Ni}_{8} \mathrm{Be}_{18}{ }_{97} \mathrm{Nb}_{3}$ amorphous alloy has a lower PDE, and the shear bands may be easy to generate, proliferate and expand under low energy barrier, resulting in uniform plasticity. That the multiple shear bands generated and crossed by room temperature compression show in Figure 6a and Figure $6 \mathrm{~b}$ In contrast to the $\left(\mathrm{Ti}_{40} \mathrm{Zr}_{25} \mathrm{Cu}_{9} \mathrm{Ni}_{8} \mathrm{Be}_{18}\right)_{97} \mathrm{Nb}_{3}$ alloy, the PDE value of $\left(\mathrm{Ti}_{40} \mathrm{Zr}_{25} \mathrm{Cu}_{9} \mathrm{Ni}_{8} \mathrm{Be}_{18}\right)_{99} \mathrm{Y}_{1}$ is about 3 times that of the $\left(\mathrm{Ti}_{40} \mathrm{Zr}_{25} \mathrm{Cu}_{9} \mathrm{Ni}_{8} \mathrm{Be}{ }_{18}\right)_{97} \mathrm{Nb}_{3}$ alloy PDE. Thus, the shear band can only be produced under high energy barriers with only a few shear bands nucleating, generating and expanding, exhibiting minimal plasticity and subsequent fracture.

\section{Conclusions}

The effects of $\mathrm{Nb}$ or $\mathrm{Y}$ addition on mechanical properties of $\mathrm{Ti}_{40} \mathrm{Zr}_{25} \mathrm{Cu}{ }_{9} \mathrm{Ni}_{8} \mathrm{Be}_{18}$ bulk amorphous alloys were investigated at room temperature. The main results are listed as follows:

Under compressive loading, the $\mathrm{Ti}_{40} \mathrm{Zr}_{25} \mathrm{Cu}_{9} \mathrm{Ni}_{8} \mathrm{Be}_{18}$ bulk amorphous alloy exhibits a fracture strength of $1896 \mathrm{MPa}$ and a plasticity of about $2.1 \%$. With addition of $\mathrm{Nb}$, the ( $\left.\mathrm{Ti}_{40} \mathrm{Zr}_{25} \mathrm{Cu}_{9} \mathrm{Ni}_{8} \mathrm{Be}_{18}\right)_{97} \mathrm{Nb}_{3}$ bulk amorphous alloy possesses the largest plastic strain of $13 \%$ and ultimate strength of $2177 \mathrm{MPa}$. If $\mathrm{Nb}$ is substituted by $\mathrm{Y}$, the ( $\left.\mathrm{Ti}_{40} \mathrm{Zr}_{25} \mathrm{Cu}_{9} \mathrm{Ni}_{18} \mathrm{Be}_{18}\right)_{99} \mathrm{Y}_{1}$ bulk amorphous alloy exhibits a fracture strength of $1990 \mathrm{MPa}$ and a plastic strain of $1.1 \%$ under compressive loading.

The PDE of the first pop-in in three bulk amorphous alloys is measured via nanoindentation test with a spherical indenter. The results show that the PDE value reduced by as much as 57 percent with $\mathrm{Nb}$ addition and increased 30 percent with $\mathrm{Y}$ addition than the PDE value of $\mathrm{Ti}_{40} \mathrm{Zr}_{25} \mathrm{Cu}{ }_{9} \mathrm{Ni}_{8} \mathrm{Be}_{18}$ bulk amorphous alloy. Smaller PDE values of the ( $\left.\mathrm{Ti}_{40} \mathrm{Zr}_{25} \mathrm{Cu}_{9} \mathrm{Ni}_{8} \mathrm{Be}_{18}\right)_{97} \mathrm{Nb}_{3}$ bulk amorphous alloy result in greater plasticity with the initiation and propagation of multiple shear bands. On the contrary, the brittle ( $\left.\mathrm{Ti}_{40} \mathrm{Zr}_{25} \mathrm{Cu}_{9} \mathrm{Ni}_{8} \mathrm{Be}_{18}\right)_{99} \mathrm{Y}_{1}$ bulk amorphous alloy has larger PDE values. Modifying the bulk amorphous alloys with a lower PDE value represents a feasible means of improving the plasticity of bulk amorphous alloys.

Author Contributions: Shengfeng Shan conceived and designed the experiments; Shengfeng Shan and Bing Zhang performed the experiments; Shengfeng Shan, Yuanzhi Jia and Mingzhen Ma analyzed the data; Mingzhen Ma and Mingzhen Ma contributed materials; Shengfeng Shan wrote the paper.

Acknowledgments: This work was supported by the NSFC (Grant Nos.51434008/51671166/51471143), and RPCST of Hebei province (Grant No. QN2014156).

Conflicts of Interest: The authors declare no conflict of interest.

\section{References}

1. Inoue, A.; Takeuchi, A. Recent development and application products of bulk glassy alloys. Acta Mater. 2011, 59, 2243-2267.

2. Yang, W.; Sun, B.; Zhao, Y.; Li, Q.; Hou, L.; Luo, N.; Dun, C.; Zhao, C.; Ma, Z.; Liu, H. Non-repeatability of large plasticity for Fe-based bulk metallic glasses. J. Alloy. Compd. 2016, 676, 209-214.

3. Li, J.; Wang, Y.W.; Yi, J.; Hussain, I.; Li, R.; Zhang, B.; Wang, G. Strain-energy transport during fracture of metallic glasses. J. Alloy. Compd. 2016, 680, 43-53.

4. Schuh, C.A.; Hufnagel, T.C.; Ramamurty, U. Mechanical behavior of amorphous alloys. Acta Mater. 2007, $55,4067-4109$.

5. Inoue, A. ; Ohtera, K.; Kita, K. ; Masumoto, T. Magnetic properties of Co-B-C amorphous alloys melt-quenched beyond the eutectic regime. Japan J. Appl. Phys. 1988, 63, 3397.

6. Wang, X.; Yoshii, I.; Inoue, A.; Kim, Y.-H.; Kim, I.-B. Bulk amorphous Ni75- xNb5MxP20- yBy (M=Cr, Mo) alloys with large supercooling and high strength. Mater. Trans. JIM 1999, 40, 1130-1136.

7. Liu, L.; Zhang, T.; Liu, Z.; Yu, C.; Dong, X.; He, L.; Gao, K.; Zhu, X.; Li, W.; Wang, C. Near-Net Forming Complex Shaped Zr-Based Bulk Metallic Glasses by High Pressure Die Casting. Materials 2018, 11, 2338.

8. Frans, S. A microscopic mechanism for steady state inhomogeneous flow in metallic glasses. Acta Metall. $1977,25,407-415$. 
339 9. Argon, A. S. Plastic deformation in metallic glasses. Acta metall 1979, 27, 47-58.

340 10. Wang, W. H.; Bian, Z.; Wen, P.; Zhang, Y.; Pan, M. X.; Zhao, D. Q. Role of addition in formation and properties of Zr-based bulk metallic glasses. Intermetallics 2002, 10, 1249-1257.

11. Chen, N.; Martin, L.; Luzguine-Luzgin, D. V.;Inoue, A. Role of alloying additions in glass formation and properties of bulk metallic glasses. Materials 2010, 3, 5320-5339.

12. Inoue, A. Bulk amorphous and nanocrystalline alloys with high functional properties. Mater. Sci. Eng., A 2001, 304, 1-10.

13. Cai, A.; Ding, D.; Liu, Y.; Wu, H.; An, W.; Zhou, G.; Luo, Y; Peng, Y. A series of Zr-based bulk metallic glasses with room temperature plasticity. Materials 2016, 9, 408.

14. Liu, R. S.; Li, J. Y. On the structural defects and microscopic mechanism of the high strength of amorphous alloys. Mater. Sci. Eng., A, 1989, 114, 127-132.

15. Conner, R. D.; Li, Y.; Nix, W. D.; Johnson, W. L. Shear band spacing under bending of Zr-based metallic glass plates. Acta Mater. 2004, 52, 2429-2434.

16. Sattler, K.D. ; Handbook of Nanophysics: Functional Nanomaterials, CRC Press, 2010.

17. Yan, X. Q.; Huang, X. M.; Uda, S.; Chen, M. W. Effect of heavy boron doping on pressure-induced phase transitions in single-crystal silicon. Appl. Phys. Lett. 2005, 87(19), 191911.

18. Pan, D.; Nieh, T. G.; \& Chen, M. W. Strengthening and softening of nanocrystalline nickel during multistep nanoindentation. Appl. Phys. Lett. 2006, 88, 161922.

19. Bei, H.; Lu, Z. P.; George, E. P. Theoretical strength and the onset of plasticity in bulk metallic glasses investigated by nanoindentation with a spherical indenter. Phys. Rev. let. 2004, 93, 125504.

20. Wang, K.; Pan, D.; Zhang, W.; XM, W.; Inoue, A. Measuring elastic energy density of bulk metallic glasses by nanoindentation.Mater. Trans. 2006, 47, 1981-1984.

21. Schuh, C. A.; Nieh, T. G. A survey of instrumented indentation studies on metallic glasses. J. Mater. Res. 2004, 19, 46-57.

22. Wang, K.; Chen, M. W.; Pan, D.; Fujita, T.; Zhang, W., Wang, X. M.; Inoue, A. Plastic deformation energy of bulk metallic glasses. Mater. Sci.Eng., B 2008, 148, 101-104.

23. Johnson, K. L. Contact mechanics cambridge univ. Press, Cambridge 1985, 95

24. Hay,J.L.;Pharr, G.M.;Kuhn, H.; Medkin,D. ASM Handbook, Volume 8, Mechanical Testing and Evaluation,2000

25. Qiao, J. W.; Zhang, Y.;Liaw, P. K. Serrated flow kinetics in a Zr-based bulk metallic glass. Intermetallics 2010, 18, 2057-2064.

26. Lewandowski, J. J.;Greer, A. L. Temperature rise at shear bands in metallic glasses. Nat. mater. $2006,5,15$.

27. Stolpe, M.; Kruzic, J. J.;Busch, R. Evolution of shear bands, free volume and hardness during cold rolling of a Zr-based bulk metallic glass. Acta Materialia 2014, 64, 231-240.

28. Schuh, C. A.;Nieh, T. G.A nanoindentation study of serrated flow in bulk metallic glasses. Acta Materialia 2003, 51, 87-99.

29. Packard, C. E.;Schuh, C. A.; Initiation of shear bands near a stress concentration in metallic glass. Acta Materialia 2007, 55, 5348-5358. 